\title{
TESTING THE ACTIVITY OF PEROXIDASE ENZYMES IN DRY PASTAS CONTAINING MILLET FLOUR AND CONTROLLING THEIR PRODUCTION AND STORAGE
}

\author{
I. SzedLjaK ${ }^{\text {a }}$, K. SzÁntainé KöHegYi and M. Tóth ${ }^{\mathrm{b}}$ \\ a Department of Grain and Industrial Plant Technology, Faculty of Food Science, \\ Corvinus University of Budapest, H-1118, Budapest, Villányi út 29-43. Hungary \\ ${ }^{\mathrm{b}}$ Department of Food Engineering, Faculty of Food Science, \\ Corvinus University of Budapest, H-1118, Budapest, Ménesi út 45. Hungary
}

(Received: 30 May 2013; accepted: 19 November 2013)

\begin{abstract}
Millet (Panicum miliaceum L.) is more resistant to climatic and soil conditions but the yields are lower than in wheat (Triticum aestivum L.), therefore its cultivation was given up for decades in Hungary. Millet is a suitable raw material for the production of pasta products without using eggs and it has other advantageous physiological effects, therefore its cultivation in Hungary is expected again. Millet is a gluten free cereal so it is not able to create viscoelastic protein network. During the biochemical studies the activity of enzymes (peroxidase, polyphenol oxidase) influencing the colour of the flour, flour mixtures (T. aestivum L., Triticum durum L., P. miliaceum L.), and pasta products were examined. Oxidoreductases in wheat flour have always been of interest to cereal chemists. The effects of peroxidase (EC 1.11.1.7) (POX) are much less thoroughly documented, although they are reported to have a relatively high level of activity in different flours. These days there are also insufficient research data on how the millet in dry pasta modifies the enzyme activity and the storage stability and shelf life of dry pasta products.
\end{abstract}

Keywords: gluten free, enzyme, peroxidase, polyphenol oxidase, dry pasta, egg pasta

The excellent nutritional and safety qualities of pasta products are widely known, especially in the Mediterranean countries. In Hungary, wheat (T. aestivum L., T. durum L.) is the most important cereal and the popularity of its pasta products is growing. Durum wheat (T. durum L.) is the best raw material for processing into pasta products due to its unique colour, flavour, and cooking quality. The colour of pastas is an essential factor in their quality classification. The colour of pasta products can be influenced by several factors: the quality of wheat (T. aestivum L., T. durum L.) and other added raw materials (millet), egg content, pasta making technologies, shape of pasta products, and pasta drying technologies. Millet is a suitable raw material for the production of pasta products without using eggs and it has other advantageous physiological effects, therefore its cultivation in Hungary is demanded again.

Millets rank $6^{\text {th }}$ in the world cereal grain production. Millet (P. miliaceum) is a commonly cultivated staple cereal crop in Africa and Asia, forming a substantial part of the farming economy (SoH et al., 2002).

In addition it is a rich source of nutrients; millet grains have an abundance of phytochemicals, particularly phenolic compounds. Phenolic compounds in millets are found in the soluble and insoluble-bound forms. Free phenolic acids are found in the outer layers of the kernel (pericarp, testa, and aleurone), whereas the bound phenolic acids are associated with the cell walls (HAHN et al., 1984). Both hydroxybenzoic and hydroxycinnamic acids and

\footnotetext{
* To whom correspondence should be addressed.

Phone: +36-1-482-6236, fax: +36-1-482-6355; e-mail: ildiko.szedljak@uni-corvinus.hu
} 
their derivatives are notably present in different types of millet grains in varying proportions. Meanwhile, flavonoids exist mainly in the free form. Data show wide variation in both the phenolic content and antioxidant capacity of millet grains. Furthermore, millet grain phenolics are bio-accessible, possess bioactivities against several pathophysiological conditions and may serve as potential natural sources of antioxidants in food and biological systems. The condensed tannins in millet may approach or exceed the antioxidant levels of fruit and vegetables (Dykes \& RoONey, 2006). However, the use of millets, as nutraceuticals and special foods in disease risk reduction and overall health and wellness is warranted (SHAHIDI \& ChandRasekara, 2013).

Their health promoting properties, in particular their antioxidant activity, and their use as nutraceuticals and in functional foods are reviewed in the paper by DYKES and RoONEY (2006). Millet contains twice as much vitamin $B_{1}$ as rice of the same amount, the content of vitamin $\mathrm{B}_{2}$ is also twice as much as that of rice. Because millet has a high content of iron, it is helpful for the postpartum women to enrich blood and restore physical strength.

The nutritive analysis of millets proves that millets score highly over the other grains. Compared to rice, they have 30 to $300 \%$ more nutritional elements, such as calcium, minerals, iron, fibre, beta carotene, and many other micronutrients (Millet Network of INDiA, 2009). The grains have relatively high indigestible fibre content because the seeds are enclosed in hulls that are difficult to remove by conventional milling processes (BRINK \& BELAY, 2006).

Most grains do not contain carotene, but 100 grams of millet contains 0.12 milligrams of carotene, and it also contains the most abundant vitamin $\mathrm{B}_{1}$ among all the grains. As a result, millet is an ideal natural colourant in foods, e.g. dry pasta.

The colour properties of pastas are also determined by some chemical and biochemical factors, e.g. their polyphenol oxidase (PPO) and peroxidase (POX) activity and total phenol content. These components derive from the flour used. The quinone derivatives synthesized from the total phenol content with molecular oxygen by PPO can polymerize spontaneously to different brown pigments (e.g. melanin). During these reactions undesirable toxic active oxygen species could be formed and some of them can be eliminated by POX. All of these parameters are almost equally responsible for the colour properties and nutrition value of different dried pastas.

The main purpose of our work was to test and document the activity of oxidative enzymes in dry pastas immediately after manufacture and before expiration date, because the oxidative enzymes in grains are regarded as major factors in time-dependent darkening and discoloration of wheat food products during processing or storage. The darkening phenomena of products reduce the quality of products and affect consumer acceptance. Another goal was to check how the millet flour modified the enzyme activity of the raw dough and dry pasta during storage. The biochemical properties of different quality but the same shaped pasta products made from wheat flours (T. aestivum L., T. durum L.) and millet flour with different egg content were compared. These pasta products were made by small-scale technology and tested for 12 months. Further purpose was to check the sensory properties of pasta products at the beginning and the end of storage. 


\section{Materials and methods}

\subsection{Materials}

All flours used for processing pasta were purchase from Hungarian market. Dry pastas were made of different flours and water. The codes of dry pastas and their flour compositions are shown in Table 1.

Table 1. Dry pasta sample codes

\begin{tabular}{|c|c|c|c|c|}
\hline \multirow[t]{2}{*}{ Flour composition of pastas } & \multicolumn{4}{|c|}{ Dry pasta sample codes } \\
\hline & 0 egg & 2 eggs & 4 eggs & 6 eggs \\
\hline $100 \%$ T. durum & $\mathrm{Td} 0$ & $\mathrm{Td} 2$ & $\mathrm{Td} 4$ & Td6 \\
\hline $100 \%$ T. aestivum & $\mathrm{Ta} 0$ & $\mathrm{Ta} 2$ & Ta4 & Ta6 \\
\hline $70 \%$ T. durum-30\% P. miliaceum & $70 \mathrm{Td} 30 \mathrm{Pm} 0$ & $70 \mathrm{Td} 30 \mathrm{Pm} 2$ & 70Td 30Pm4 & 70Td 30Pm6 \\
\hline $60 \%$ T. durum-40\% P. miliaceum & $60 \mathrm{Td} 40 \mathrm{Pm} 0$ & $60 \mathrm{Td} 40 \mathrm{Pm} 2$ & $60 \mathrm{Td} 40 \mathrm{Pm} 4$ & $60 \mathrm{Td} 40 \mathrm{Pm} 6$ \\
\hline $50 \%$ T. durum-50\% P. miliaceum & $50 \mathrm{Td} 50 \mathrm{Pm} 0$ & $50 \mathrm{Td} 50 \mathrm{Pm} 2$ & $50 \mathrm{Td} 50 \mathrm{Pm} 4$ & 50Td 50Pm6 \\
\hline $70 \%$ T. aestivum-30\% P. miliaceum & 70Ta $30 \mathrm{Pm} 0$ & 70Ta 30Pm2 & 70Ta 30Pm4 & 70Ta 30Pm6 \\
\hline $60 \%$ T. aestivum $-40 \%$ P. miliaceum & $60 \mathrm{Ta} 40 \mathrm{Pm} 0$ & $60 \mathrm{Ta} 40 \mathrm{Pm} 2$ & $60 \mathrm{Ta} 40 \mathrm{Pm} 4$ & $60 \mathrm{Ta} 40 \mathrm{Pm} 6$ \\
\hline $50 \%$ T. aestivum-50\% P. miliaceum & 50Ta 50Pm0 & $50 \mathrm{Ta} 50 \mathrm{Pm} 2$ & 50Ta 50Pm4 & $50 \mathrm{Ta} 50 \mathrm{Pm} 6$ \\
\hline
\end{tabular}

The pastas with different flour composition were made without egg and with 2, 4, or 6 fresh eggs (i.e. 2, 4, or 6 eggs were added to $1 \mathrm{~kg}$ flour). Hungarian consumers traditionally prefer dry pastas made with eggs. We could not produce pasta made of $100 \%$ P. miliaceum flour, because it is gluten free flour and we did not want to add any food additives to dry pasta. Each pasta sample was manufactured spindle shaped. These pasta products were made by small-scale technology and dried by the same drying method $\left(40-60{ }^{\circ} \mathrm{C}\right)$. The drying parameters can be seen in Table 2 .

Table 2. Parameters of pasta drying

\begin{tabular}{lcc}
\hline Drying period $(\mathrm{h})$ & Relative humidity $(\%)$ & Temperature $\left({ }^{\circ} \mathrm{C}\right)$ \\
\hline 0.00 & 36 & 70 \\
2.00 & 50 & 72 \\
4.00 & 59 & 68 \\
6.00 & 64 & 62 \\
8.00 & 65 & 55 \\
10.00 & 54 & 45 \\
12.00 & 47 & 34 \\
14.00 & 44 & 20 \\
\hline
\end{tabular}




\subsection{Methods}

The moisture content was determined in a drying oven. The oven was thermostatically controlled by a heating chamber capable of maintaining a temperature of $110 \pm 5^{\circ} \mathrm{C}$.

Each flour, flour mixture, and dry pasta product unstored and stored were sampled. The samples were homogenized and the extracts $\left(0.10 \mathrm{~g} \mathrm{ml}^{-1}\right.$ in water after centrifugation for 10 min at $4{ }^{\circ} \mathrm{C}$ at 10000 r.p.m.) were made. Chemicals were purchased from Sigma-Aldrich Co. and REANAL Finechemical Co.

POX activity of the extracts was determined using $o$-dianisidine as hydrogen donor in sodium acetate ( $\mathrm{pH}$ 5.1) (BJORKSTEIN, 1968). One unit of POX activity was defined as the amount of enzyme that caused decomposition of 1 mole hydrogen peroxide in the reaction mixture $(1.0 \mathrm{ml})$ in $1 \mathrm{~min}$. All results were calculated in terms of dry matter of flour and pasta samples.

Sensory properties of cooked pasta were evaluated by naive panellists ( 25 persons) using a 5-point category scale (HunGARIAN STANDARD, 1985). External appearance (especially colour of cooked pasta), taste, smell, and consistency of pasta samples were assessed.

\section{Results and discussion}

We examined activities of peroxidase (POX) in different kinds of flours and in pasta samples immediately after manufacturing as well as during the 12-month storage period. All analyses were performed at least in quintuplicate. Enzyme activity values were calculated accordingly (mean values). Standard deviation was within $\pm 5 \%$.

POX enzyme activities have been measured in all flour samples, as well as in pastas prepared without egg and with eggs and stored under the same storage conditions. POX activity was in the range of 283-469 $\mathrm{U} \mathrm{g}^{-1}$ in aestivum flour, $56-121 \mathrm{U} \mathrm{g}^{-1}$ in durum flour. The millet flour samples had got significantly higher POX activity, they were between 435-678 $\mathrm{Ug}^{-1}$.

The presented POX activity values of dry pastas after manufacturing (Fig. 1) and during long-term storage (Figs 2-3) are mean values of the biochemical analysis.

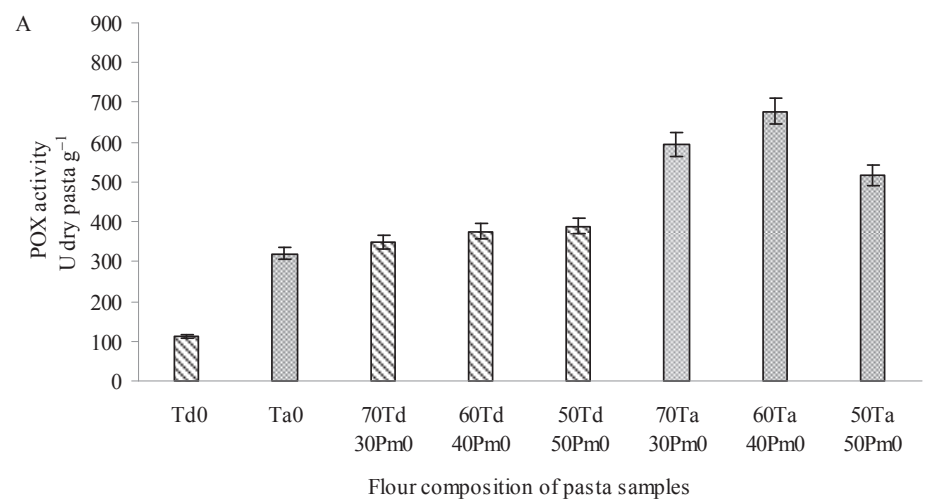

Fig. 1. POX activity of pastas made from different flour mixtures A: without egg; B: with 2 eggs; C: with 4 eggs; D: with 6 eggs 


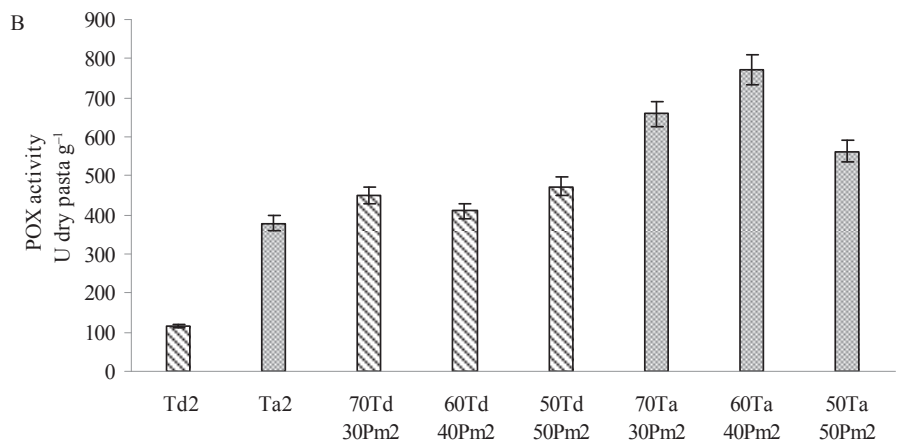

Flour composition of pasta samples

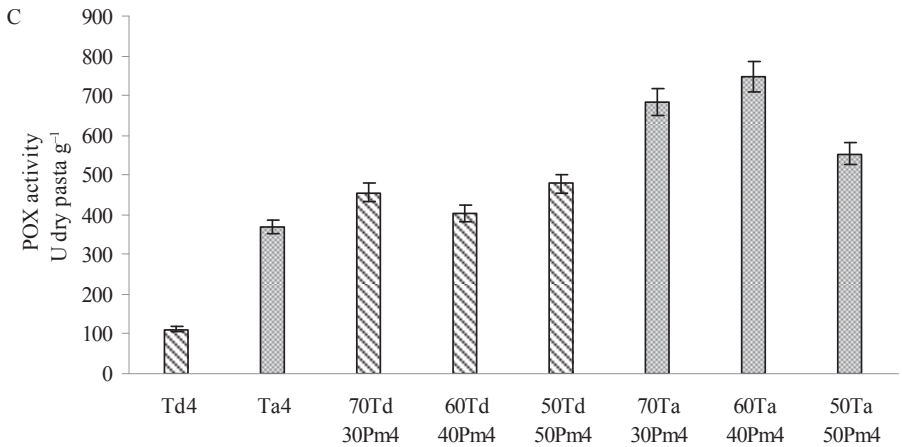

Flour composition of pasta samples

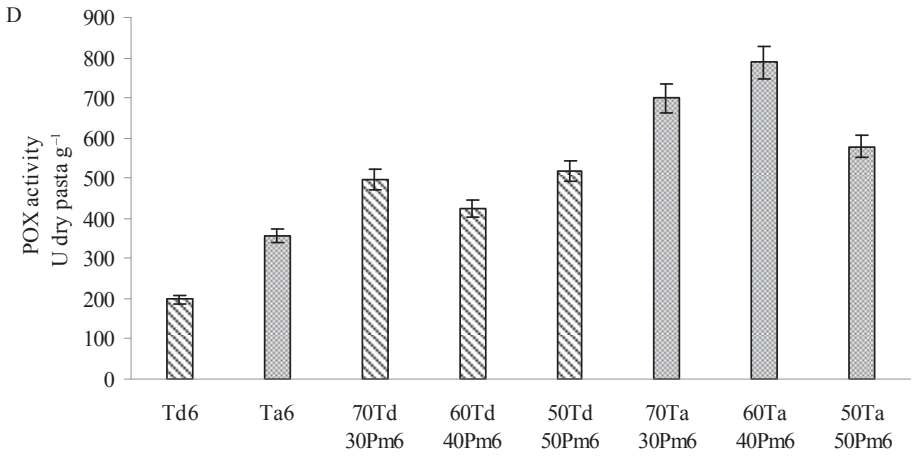

Flour composition of pasta samples

Fig. 1. cont.

Figure 1 represents POX activity of dry pastas made from different kinds of flour and their egg content right after manufacturing. Enzyme activities of pasta samples without eggs (Fig. 1A) were in the range of 112-678 $\mathrm{U} \mathrm{g}^{-1}$. 
The lowest enzyme activities of pastas were measured in samples only containing durum flour. The enzyme activities of pasta samples produced with durum and aestivum flour differ significantly. POX activity of pastas made from $100 \%$ aestivum flour was three times higher than that of $100 \%$ durum flour. The use of millet flour raised the POX activity of pastas. POX activity of pastas containing $50 \%$ of millet flour and $50 \%$ T. aestivum flour proved to be lower $\left(518 \mathrm{U} \mathrm{g} \mathrm{g}^{-1}\right)$ than pastas containing 30\% of millet flour and $70 \%$ T. aestivum flour $\left(596 \mathrm{U} \mathrm{g}^{-1}\right)$.

As the samples were always produced with fresh eggs, and these eggs might have been of different masses, ratios of ovalbumin and yolk, qualities, exactly the same chemical composition of pastas could not be ensured. However, increasing the egg content resulted in a relatively low change in the enzyme activity values (Figs 1B, 1C, 1D). Even increasing the egg content from 2 to 6 eggs did not result in any significant change in the enzyme activity. The POX activity in fresh made pasta samples was primarily determined by flour composition.

\subsection{Storage experiences}

Fig. 2A describes POX activity of pastas made from T. durum and P. miliaceum flour mixture without egg during the storage period. POX values showed significant increase after the $3^{\text {rd }}$ month of storage. When the pastas contained 100\% durum flour, their enzyme activities increased ten times during their 12-month storage period. Though the samples containing millet flour had a higher enzyme activity at the beginning of the storage period, at the end of the storage the activity was not higher than that of the samples containing only durum flour.

POX activity of pastas made of T. aestivum and P. miliaceum flour mixture without egg during storage period can be seen in the Fig. 3A.

The pastas produced from aestivum flour showed higher enzyme activity (Fig. 3A) than the pastas prepared from durum flour (Fig. 2B) also in the beginning and in the $1^{\text {st }}$ and $2^{\text {nd }}$ month of storage. Enzyme activity value of pastas containing $100 \%$ aestivum flour increased five times higher during 12 months. POX activity of pasta samples containing $40 \%$ millet flour increased from $678 \mathrm{U} \mathrm{g}^{-1}$ to $2546 \mathrm{U} \mathrm{g}^{-1}$ by the end of the storage period. Enzyme activity values had increased significantly from the $5^{\text {th }}-6^{\text {th }}$ month of storage if they contained millet flour as well.

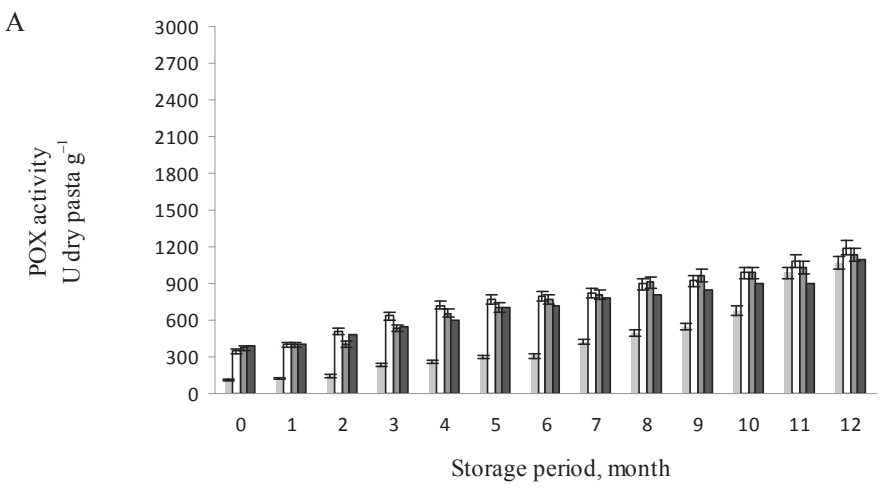

Fig. 2. POX activity of pastas made from $T$. durum and P. miliaceum flour mixture.

A: without egg; : Td 0; $\square: 70$ Td 30 Pm; $: 60$ Td 40 Pm; 50 Td 50 Pm
B: with 2 eggs. $:$ Td 2; $\square: 70$ Td 30 Pm 2, 60 Td 40 Pm 2; $: 50$ Td 50 Pm 2
C: with 4 eggs. $:$ Td 4; $\square: 70$ Td 30 Pm 4; 60 Td 40 Pm 4; 50 Td 50 Pm 4
D: with 6 eggs. $\quad$ : Td 6; $\square: 70$ Td 30 Pm 6; : 60 Td 40 Pm 6; 50 Td 50 Pm 6



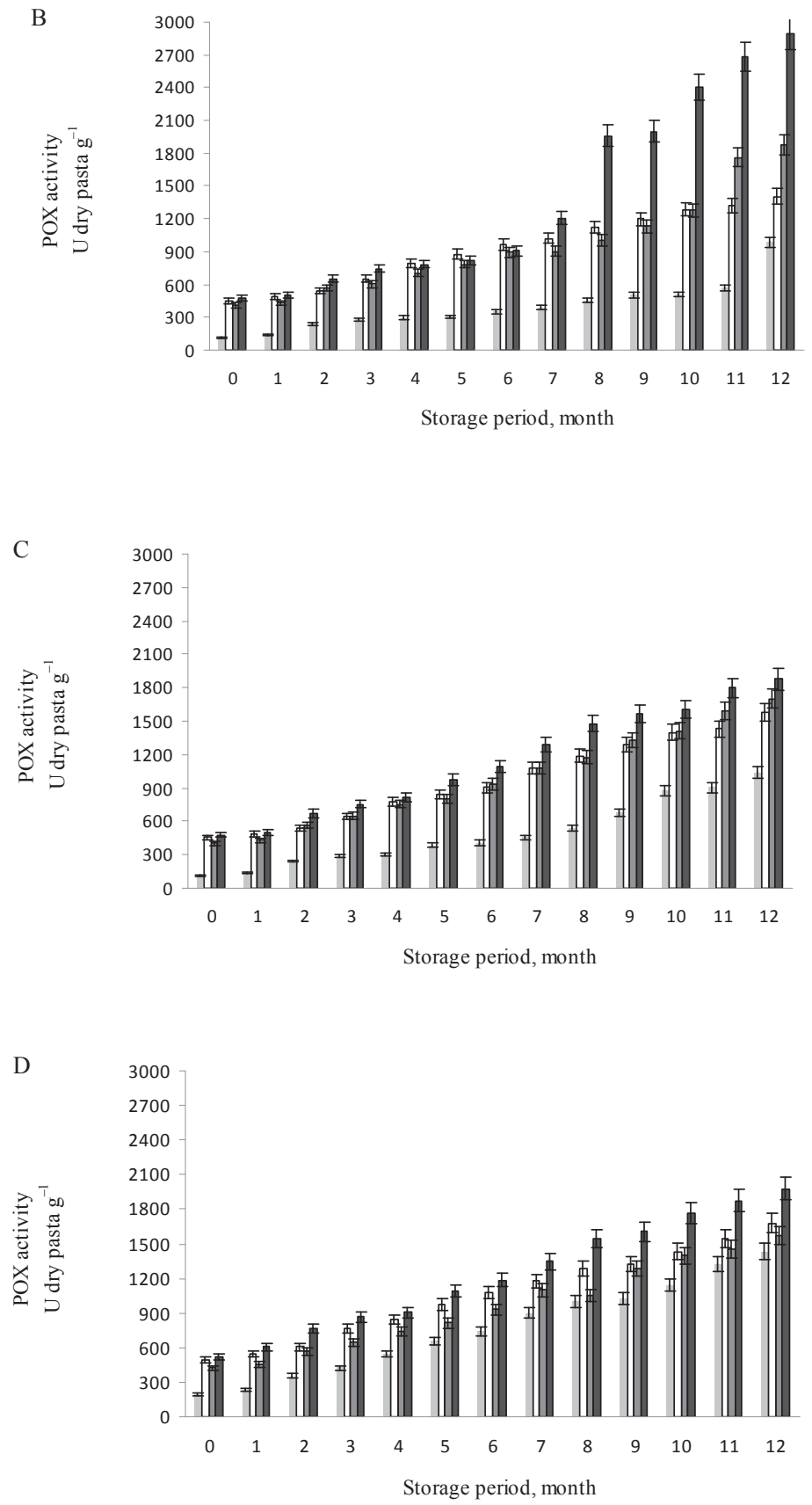

Fig 2. cont. 

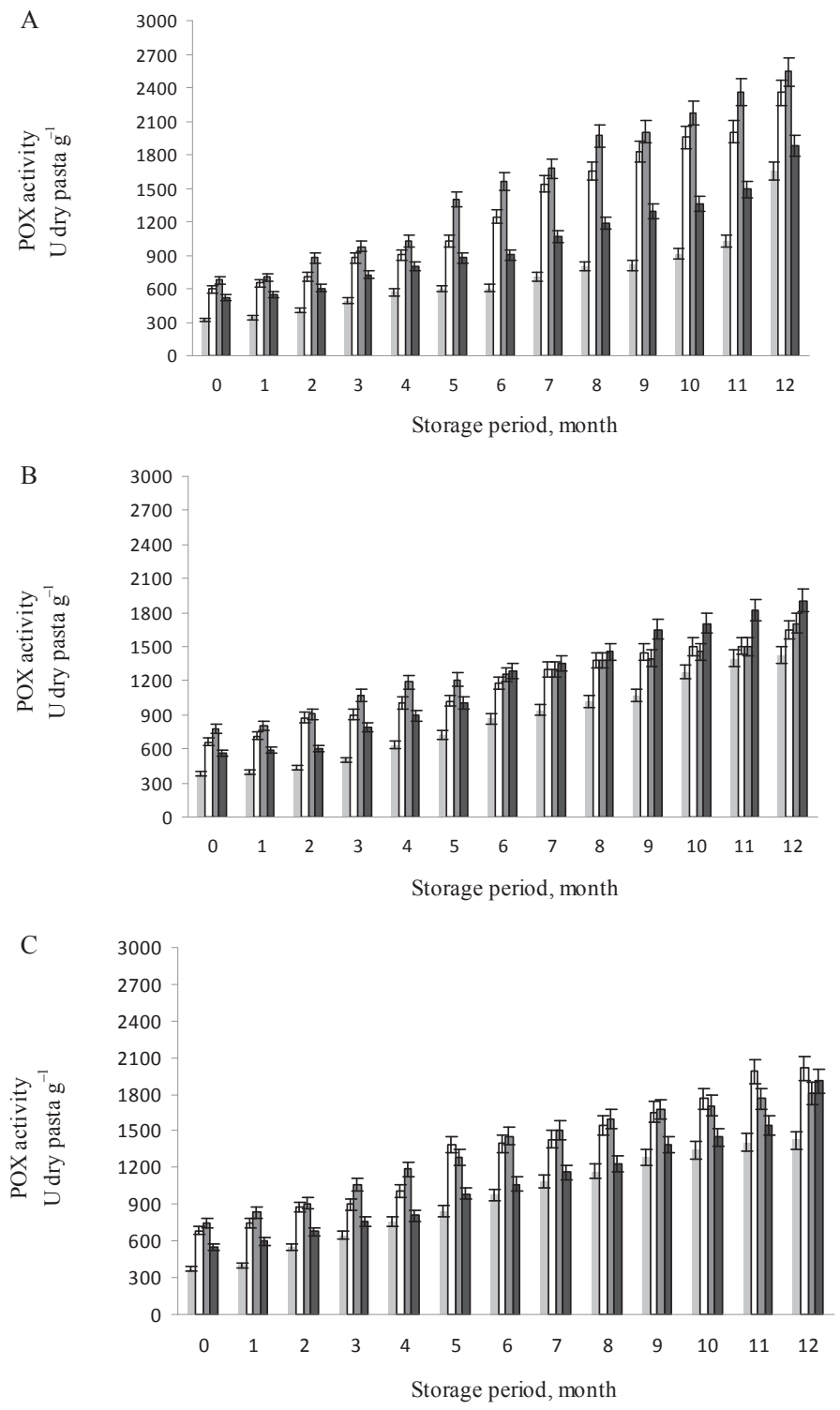

Fig. 3. POX activity of pastas made from T. aestivum and P. miliaceum flour mixture.

A: without egg; : Ta 0; $\square: 70$ Ta 30 Pm; $\square: 60$ Ta 40 Pm; $\square 50$ Ta 50 Pm B: with 2 eggs. : Ta 2; $\square: 70$ Ta 30 Pm 2, : 60 Ta 40 Pm 2; 50 Ta 50 Pm 2 C: with 4 eggs. : : Ta 4; $\square$ : 70 Ta 30 Pm 4; : 60 Ta 40 Pm 4; $\square: 50$ Ta 50 Pm 4 D: with 6 eggs. I: Ta 6; $\square$ : 70 Ta 30 Pm 6; $\square: 60$ Ta 40 Pm 6; $\square: 50$ Ta 50 Pm 6 


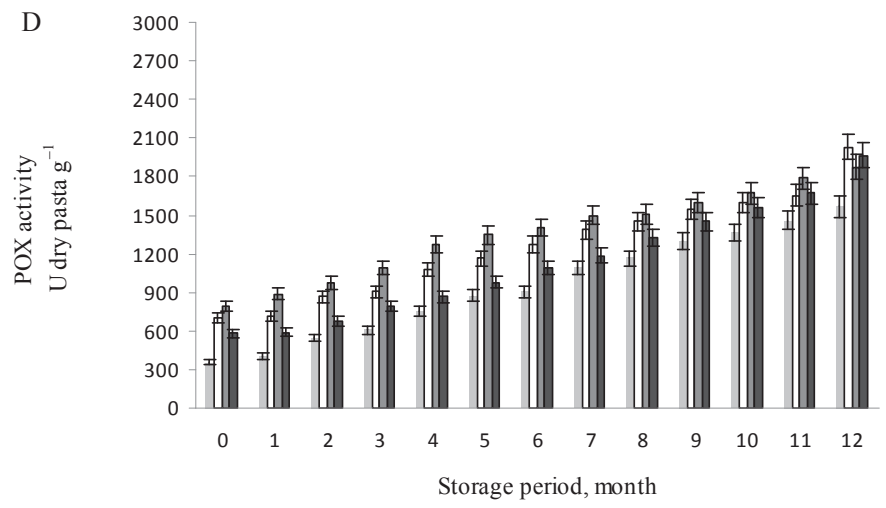

Fig. 3. cont.

In Figure 2B the enzyme activity values of pastas made from durum and millet flour with 2 eggs can be seen. When the samples contained only durum flour (Fig. 2A) their enzyme activities showed higher values than the samples with 2 eggs (Fig. 2B) at the $12^{\text {th }}$ month of storage. POX activity of samples containing millet flour changed from $410 \mathrm{U} \mathrm{g}^{-1}$ to 2897 $\mathrm{U} \mathrm{g}^{-1}$. On the other hand, samples containing 50\% millet flour showed a sudden rise of activity in the $8^{\text {th }}$ month and a further rise was observed by the end of the $12^{\text {th }}$ month $(2897$ $\mathrm{U} \mathrm{g}^{-1}$ ). Such an activity increase could be seen only with these samples, and a different odour character was experienced as well. This phenomenon could not be observed with the other samples (Figs 2A, 2C, 2D-3A, 3B, 3C, and 3D), the unfavourable change of odour could have been caused by the eggs.

At $60-70 \%$ T. aestivum flour content POX enzyme activity values had increased significantly in the $5^{\text {th }}$ month of storage (Fig. 3A), by the end of storage the activity values were $2354 \mathrm{U} \mathrm{g}^{-1}$ and $2546 \mathrm{U} \mathrm{g}^{-1}$, respectively.

POX activity values of pasta prepared from aestivum flour with 2 eggs showed a gradual rise (Fig. 3B). By the end of storage there was no significant difference between the POX activity of pastas made from aestivum flour and millet flour (Fig. 3B).

Considering Figures 3B, 3C, and 3D, we can say that the enzyme activity values were similar, showing $1800-2000 \mathrm{U} \mathrm{g}^{-1}$ by the end of the storage regardless of whether 2 , 4 , or 6 eggs were used.

\subsection{Sensory assessment}

All pasta products complied with the Hungarian STANDARD (1985). According to the results of sensory evaluation, all pastas with and without eggs were classified into quality class 1 at the beginning of the storage period. The judgement of external appearance of pasta samples was better when we added millet flour into the pasta dough. The panellists gave maximum value (20 points) for pasta samples containing 30\% millet flour and $70 \%$ durum flour with four eggs. The same sample got the highest value (19 point) at the end of the storage. The pasta samples containing 50\% durum and 50\% millet flour with two eggs (50Td50Pm2) were reclassified into quality class 2 (14 points) at the $12^{\text {th }}$ month. The decreasing quality of $50 \mathrm{Td} 50 \mathrm{Pm} 2$ was also confirmed by POX activity values. 


\section{Conclusions}

POX enzyme activity in aestivum, durum, and millet containing dry pasta products was studied. The POX activity values of aestivum and durum were different. POX activity in aestivum flour was three or four times higher than in durum flour. Millet flour added pasta dough had an increased POX activity in all cases. It was found, that egg content did not result in any significant change in enzyme activity, so POX activity in fresh made pasta samples was clearly determined by flour composition. During storage the POX activity gradually increased. Pastas made from aestivum and millet flour mixture without eggs showed approximately two times higher POX enzyme activity than durum and millet flour containing pastas by the end of the storage period. It was found that regardless of the fact whether 2, 4, or 6 eggs were used, the enzyme activity values were similar, showing $1800-2000 \mathrm{U} \mathrm{g}^{-1}$ by the end of the storage.

Summarizing the enzyme activity results, we proved that POX activity is growing in pasta samples during storage. Considering POX activity values of pastas, the nutrition values of raw materials, and the results of the sensory tests we suggest the usage of $30 \%$ millet and $70 \%$ T. durum flour mixture with or without eggs.

The authors acknowledge the financial help of the GOP-1.1.1-09/01 and the support of Füri Pasta and Food Marketing Ltd.

\section{References}

Bjorkstein, H. (1968): Participation of horseradish oxyperoxidase (compound III) in interenzymic reaction steps. Biochem. Biophys. Acta, 151, 309-311.

Brink, M. \& Belay, G. (2006): Plant resources of tropical Africa. Cereals and Pulses Prota Foundation/ Backhuys Publishers, Leiden/CTA Wageningen, Netherlands, pp. 122-126.

Dykes, L. \& Rooney, L.W. (2006): Sorghum and millet phenols and antioxidants. J. Cereal Sci., 44, $236-251$.

Hahn, D.H., Rooney, L.W. \& EARP, C.F. (1984): Tannins and phenols of sorghum. Cereal Foods World, 29, 776779 .

Hungarian Standard (1985): Száraztészták vizsgálati módszerei. Fizikai vizsgálatok (Test methods of pastry products. Testing physical properties). MSZ 20500-1:1985

Millet Network of India, Deccan Development Society \& FiAn, India (2009): Millets: Future of food and farming. Booksline A, SRAS Publication, Hyderabad, India, 16 pages.

Shahidi, F. \& Chandrasekara, A. (2013): Millet grain phenolics and their role in disease risk reduction and health promotion: A review. J. Funct. Foods, 2, 570-581.

SoH, H.S., LeE, S.P. \& HA, Y.D. (2002): Total lipid content and fatty acid composition in Setaria italica, Panicum miliaceum and Sorghum bicolor. J .East Asian Soc. Diet Life, 12, 123-128. 